\title{
Hundred years of the boundary layer - Some aspects
}

\author{
E G TULAPURKARA \\ Department of Aerospace Engineering, Indian Institute of Technology Madras, \\ Chennai 600 036, India \\ e-mail: egt@ae.iitm.ac.in
}

MS received 20 January 2005; revised 2 August 2005

\begin{abstract}
The concept of the boundary layer was proposed by Ludwig Prandtl in 1904. This concept has allowed prediction of skin friction drag, heat transfer from the wall and separation of the boundary layer, which in turn enables proper design of airplanes, ships, other vehicles and equipment through/around which fluid flow takes place. The centenary of the proposal by Prandtl is being celebrated in various ways. This article is an attempt at presenting some of the developments in boundary layers. The article begins with a brief description of Prandtl's work. Subsequent sections deal with (a) a brief account of his 1904 paper, (b) some aspects of developments in boundary layer research and applications, (c) discussion of a few contributions from India in the area of boundary layers, and concluding remarks.
\end{abstract}

Keywords. Boundary layers; centenary; history; Prandtl.

\section{Introduction}

Towards the end of nineteenth century, researchers in fluid mechanics were divided into two broad groups, viz. those engaged in the study of hydrodynamics, which dealt with inviscid fluid flow, and those studying hydraulics. Hydrodynamics, though mathematically elegant, was not able to predict the drag experienced by bodies moving in fluids. This is known as D'Alembert's paradox. On the other hand, hydraulics offered solutions to practical problems but was based mainly on empirical data.

This situation changed radically when Ludwig Prandtl proposed his boundary layer theory in 1904. This theory states that due to the no-slip condition, the velocity on the surface of a stationary body is zero, but the velocity given by inviscid flow theory would be reached within a thin layer called the boundary layer. Since the layer is thin, the velocity gradients are large and the shear stresses are not negligible even when viscosity is small. The thinness of the boundary layer enables simplifications like rendering the governing equations parabolic and imposing external pressure on the boundary layer. The theory further showed that separation of flow is decided mainly by a streamwise pressure gradient in the external flow. Though originally developed for laminar flow, it was soon extended to turbulent flow. The theory gained acceptance-after some years and helped in the better design of airplanes, engine components and many other equipment involving fluid flow. The boundary layer concept developed rapidly and is now applied in almost all branches of engineering. The theory has also led to the 
development of mathematical tools like method of matched asymptotic expansions. This article touches upon some aspects of the developments in boundary layers.

\section{Prandtl, the man}

The material of this section has been taken from Anderson (1985), Rouse \& Ince (1963), Tani (1977), Lumley \& Yaglom (2001) and various websites. Ludwig Prandtl (figure 1) was born on February 4, 1875 in Freising, Germany. His father was Alexander Prandtl, and mother, the former Magdalene Ostermann. Ludwig's father was a professor of surveying and a great lover of nature. He influenced Ludwig to observe natural phenomena and reflect on them. In 1894 Ludwig started his studies at the Technische Hochschule in Munich. He graduated from the University of Munich with a Ph.D. Prof. A Foppl was his advisor and his thesis dealt with unstable elastic equilibrium in which bending and distortion acted together.

After completing his Ph D from Munich, Prandtl joined Maschinenfabrick Augsburg as an engineer. His job was to redesign an apparatus for removing machine shavings (chips) by suction. Finding no reliable information, he got deeply involved in fluid mechanics and carried out experiments, which provided answers to some questions in his mind. He modified the design, which performed better and consumed only one-third the power required earlier. In 1901 Prandtl became Professor of Mechanics at Technische Hochschule in Hanover. He continued his study of fluid mechanics; developed boundary layer theory and became interested in supersonic flow through nozzles. In 1904 he presented the concept of the boundary layer at the Third Congress of Mathematicians at Heidelberg. Later that year, he was appointed Professor at the University of Göttingen. In 1925 he became Director of the Institute for Technical Physics and continued in that post till his death on August 15, 1953.

During 1905-1908 Prandtl carried out experiments in supersonic flow through nozzles and developed oblique shock and expansion wave theory. During 1910-1920 his efforts were concentrated mainly on low speed aerofoil and wing theory (known as the Prandtl lifting line theory). In the 1920s, he worked on compressible flow and gave the PrandtlGlauert compressibility correction. In 1925 he developed the concept of mixing length to obtain eddy viscosity in turbulent flows. In 1945 he modified the theory, which is now called the one-equation model of turbulence. He made contributions in many areas and his name is associated with: Prandtl number, Prandtl's boundary layer theory, Prandtl's lifting line

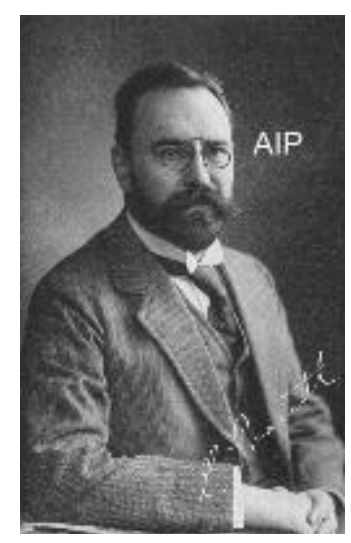

Figure 1. Ludwig Prandtl. 
theory, Prandtl-Meyer expansion function and Prandtl mixing length theory. Prandlt had many excellent students like Von Karman, Munk, Schlichting, Betz, Busemann, Polhausen, Tollmien and Ackeret. V M Ghatage, who later became the first Chief Designer at Hidustan Aeronautics Limited (HAL) and Professor at the Indian Institute of Science, Bangalore, obtained his Ph D under Prandtl in 1936. Prandtl was a gracious, studious, likable, friendly person totally engaged in things that interested him. He was an accomplished pianist. He was married to Gertrude, daughter of his adviser, Prof. Foppl. Prandtl had two daughters.

Prandtl is rightly called the father of aerodynamics but he was a very unassuming person. On the occasion of his being elected honorary member of the German Physical Society, Prandtl gave a talk entitled "My road to hydrodynamic theories". In response to Heisenberg's congratulatory remarks that Prandtl had the ability to see through equations, without calculating, what solution they may possess, he said "I should reply that I admit having no such ability, but I endeavor to gain as clear a conception as possible about the matters forming the basis of the problem and seek to understand the events. The equations do not come in until later, when I believe to have understood the problem: they are useful not only to produce quantitative information which cannot certainly be obtained by conception alone, but also to afford good means of adducing proofs for my conclusions, thus winning recognition from others".

\section{The 1904 paper}

Prandtl presented the paper entitled "Uber Flussigkeitsbewegung bei sehr kleiner Reibung" at the Third International Congress of Mathematics held in Heidelberg and published in the Proceedings of the Congress in 1905. This paper is available in English with the title of "Motion of fluid with very little viscosity" as NACA TM 452, March 1928.

According to Tani (1977), the genesis of boundary layer theory can be summarized as follows. When Prandtl was working at Maschinenfabrick Augsburg as an engineer, he arranged a conical diffuser in a large air duct but failed to achieve the desired pressure recovery. The angle of the cone was too large and the flow separated from the diffuser walls. The reason for the loss of pressure and the separation of the flow occupied Prandtl's inquiring mind and after three years the concept of boundary layer provided the answers. The 1904 paper is a brief account of just eight pages and contains features of boundary layer theory, separation of boundary layer and delay of separation by suction. The article begins with the continuity equation and N-S equation for an incompressible fluid. (Standard notations are used throughout.)

$$
\begin{aligned}
& \nabla \cdot \bar{V}=0, \\
& \frac{D \bar{V}}{D t}+\nabla P=\mu \nabla^{2} \bar{V} .
\end{aligned}
$$

These equations in scalar, non-dimensional form for steady two-dimensional flow can be written as:

$$
\begin{aligned}
& \frac{\partial U^{*}}{\partial x^{*}}+\frac{\partial V^{*}}{\partial y^{*}}=0, \\
& U^{*} \frac{\partial U^{*}}{\partial x^{*}}+V^{*} \frac{\partial U^{*}}{\partial y^{*}}=-\frac{\partial p^{*}}{\partial x^{*}}+\frac{1}{\operatorname{Re}}\left[\frac{\partial^{2} U^{*}}{\partial x^{* 2}}+\frac{\partial^{2} U^{*}}{\partial y^{* 2}}\right], \\
& U^{*} \frac{\partial V^{*}}{\partial x^{*}}+V^{*} \frac{\partial V^{*}}{\partial y^{*}}=-\frac{\partial p^{*}}{\partial y^{*}}+\frac{1}{\operatorname{Re}}\left[\frac{\partial^{2} V^{*}}{\partial x^{* 2}}+\frac{\partial^{2} V^{*}}{]} .\right.
\end{aligned}
$$




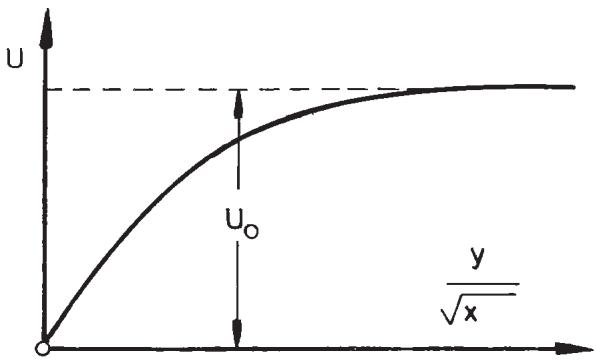

Figure 2. Boundary layer profile.

Prandtl provided (1) and (2), we present (3), (4) and (5) for the sake of explanation. Equations (1) and (2) are nonlinear partial differential equations and exact solutions can only be obtained for very slow motion, where the inertia terms can be ignored or when the viscous terms are ignored (inviscid flow). It was known that the inviscid flow equations did not predict drag experienced by bodies. To tackle this problem, Prandtl argued that the fluid adheres to the surface of the body i.e. velocity of fluid is zero on a stationary body or equal to the velocity of the body when the body is moving. However, the velocity around the body which can be obtained by the potential flow theory or inviscid flow theory, would be outside a thin layer (Prandtl called this layer a transition layer but later the term boundary layer was accepted). Since the layer is very thin the cross-stream velocity gradient is high and produces noticeable effects even for very small viscosities. Then he further argued that since the layer is thin the normal component of velocity $(V)$ is small and the external pressure gradient is impressed on the boundary layer. He stated the following boundary layer equations, which can obtained by applying order of magnitudes analysis (see Schlichting \& Gersten 2000)

$$
\begin{aligned}
& \frac{\partial U}{\partial x}+\frac{\partial V}{\partial y}=0, \\
& U \frac{\partial U}{\partial x}+V \frac{\partial U}{\partial y}+\frac{1}{\rho} \frac{d p}{d x}=v \frac{\partial^{2} U}{\partial y^{2}} .
\end{aligned}
$$

Prandtl mentions that $d p / d x$ is to be given throughout the length of body and the profile of $U$ should be given at an initial cross-section. Then the problem can be solved numerically. What he seems to imply is that the $\mathrm{N}-\mathrm{S}$ equations of elliptic nature are now converted to equations of parabolic nature. Subsequently, the paper presents the result for the problem of flow past a flat plate without giving proof. He also states that equations (6) and (7) can be simplified by using a similarity hypothesis, i.e. $U$ can be expressed as $f(y / \sqrt{ } x)$. Again without giving any details, he mentions that the resistance or the skin friction drag taken together for both sides of plate is $R=1 \cdot 1 b\left(\mu \rho l U_{o}^{3}\right)^{1 / 2}$, where $b$ is the width of plate, $l$ is length of plate and $U_{o}$ is the velocity of the undisturbed flow. He obtained the velocity profile as shown in figure 2.

Remark 1. The details of the analysis are given later in a paper by Blasius published in 1908 (See Schlichting \& Gersten 2000), who obtained the correct expression of $R=1 \cdot 328 b\left(\mu \rho l U_{o}^{3}\right)^{1 / 2}$. After obtaining the boundary layer profile, he mentions an important practical result, that in certain cases the flow separates from surfaces at a point entirely determined by external conditions as shown in figure 3. Further he says that on closer 


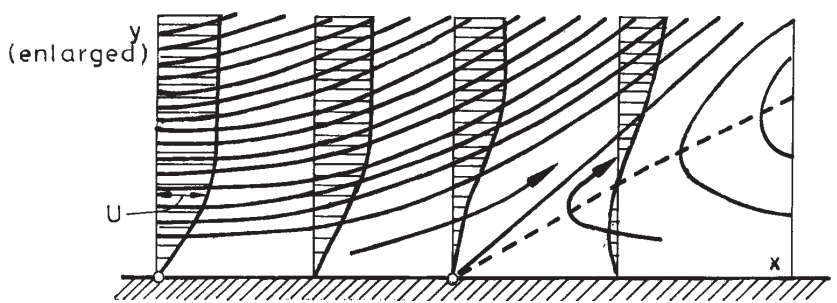

Figure 3. Boundary layer separation.

examination, the necessary condition for separation of flow is that there should be pressure increase along the surfaces in the direction of flow, which is now called adverse pressure gradient. Subsequently, Prandtl explains how shear layers would be formed behind a circular cylinder and bodies with sharp corners. To give experimental evidence, he mentions the experimental studies done in a water channel as shown in figure 4. He also shows the flow patterns behind (a) a circular cylinder, and (b) when suction is applied through a hole on the upper side of the cylinder (figure 5).

\subsection{Comments on the paper}

(1) Prandtl (1904) is a very remarkable paper as it presents (a) the concept of the boundary layer which results in the transformation of elliptic equations to parabolic equations, (b) application of the similarity hypothesis to reduce partial differential equations to ordinary differential equations, (c) a formula for friction drag on a flat plate, (d) separation dependent on external pressure gradient, (e) the idea that separation can be controlled by suction.

(2) Tani (1977) mentions that when Prandtl was asked why the paper was so short (eight pages), Prandtl explained that he was given only ten minutes for his lecture at the Congress and (that being still young) he thought he could publish only what he had had time to say.

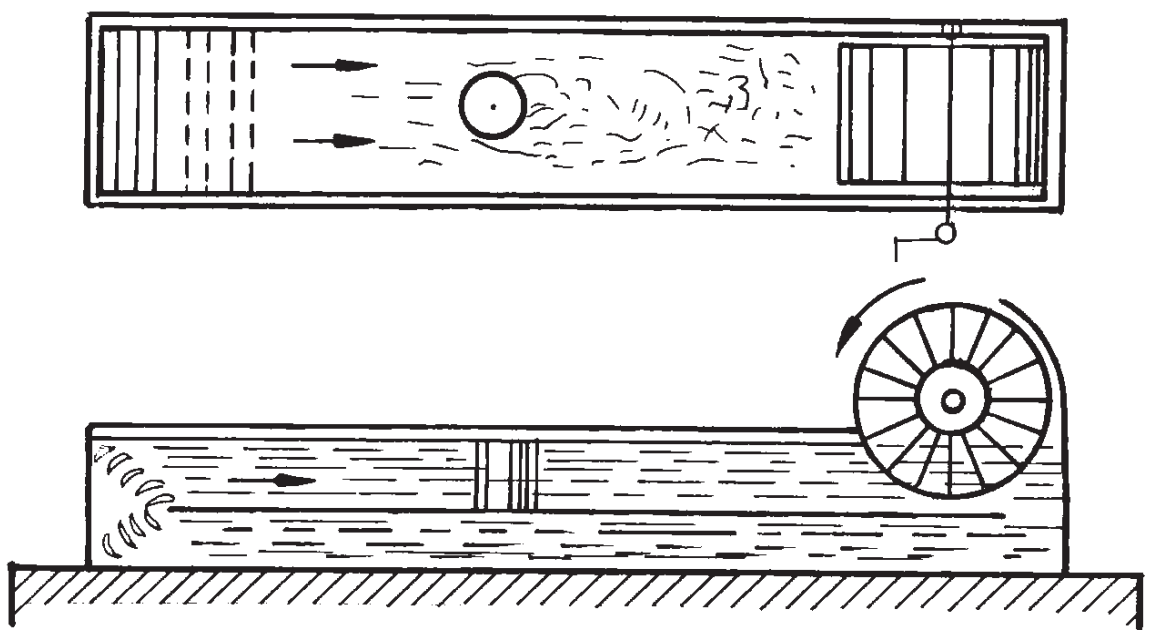

Figure 4. Prandtl's water channel. 

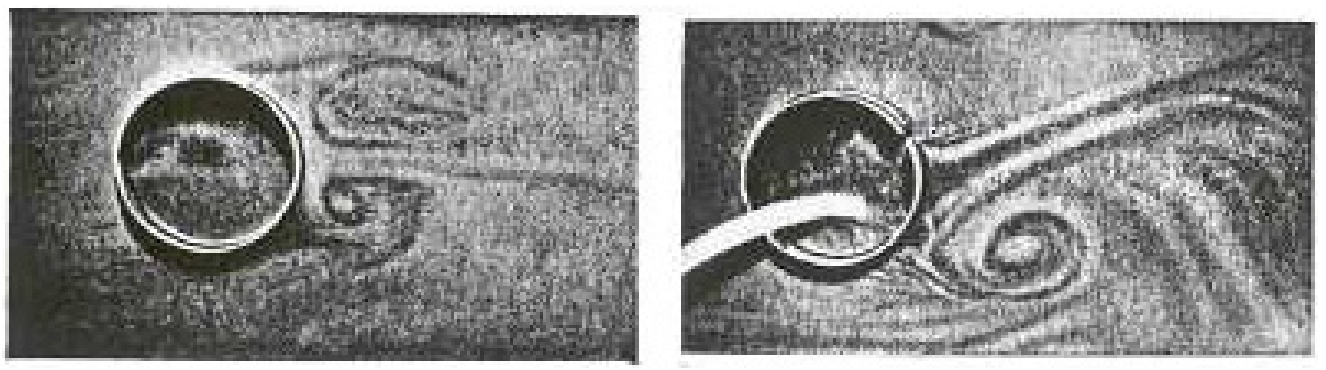

Figure 5. Flow visualization of wake behind cylinder - without (left) and with (right) suction.

\section{Some aspects of developments in boundary layer research}

After the presentation of the boundary layer concept by Prandtl in 1904, only six papers appeared in the period 1904 to 1914 (Tani 1977). Blasius (1908) presented results for boundary layers over a flat plate in a uniform stream and on a circular cylinder. Bolze (1908) reported results on boundary layer over a sphere. Prandtl (1910) applied the boundary layer concept to heat transfer problems. Heimenz (1911) presented results for boundary layer over circular cylinders with experimental pressure distributions. Toffer, (1912) presented refined calculations of cases investigated by Blasius. It may be pointed out here that when the bibliographic details of some of the investigations are not given in this article, they can be seen in Tani (1977). Prandtl (1914) explained the reduction in drag of a sphere after a certain Reynolds number, as observed by Eiffel (1912) as due to the transition of flow in the boundary layer from laminar to turbulent. All these papers originated from Göttingen. It may be added that transition to turbulence in channels and pipes was known earlier through the experiment of Reynolds in 1883 (Schlichting \& Gersten 2000). Orr and Sommerfeld had derived equations for stability in 1907 and 1908 (Schlichting \& Gersten 2000).

The important developments in the period 1914 to 1924 are: (i) Von Karman developed the following momentum integral equation, obtained by integrating (7) across the boundary layer:

$$
\frac{\mathrm{d} \theta}{\mathrm{d} x}+\frac{\theta}{U_{e}}(H+2) \frac{\mathrm{d} U_{e}}{\mathrm{~d} x}=\frac{C_{f}}{2},
$$

where $\theta, U_{e}, H$ and $C_{f}$ are momentum thickness, external velocity, shape parameter and skin friction coefficient respectively (see Schlichting \& Gersten 2000, for details). This equation permits calculation of skin friction drag needed for optimizing airfoil shapes. (ii) Tollmien (1924) reported the results of boundary layer on a rotating circular cylinder. (iii) Burger and his students (Burgher et al 1924 \& 1925) reported hot wire measurements in boundary layer. By this time (1924) the concept of the boundary layer had spread to many countries.

During the period 1924 to 1934 the spread of boundary layer research was facilitated (Tani 1977) by Tollmien (1931) article in Handbuch der experimental Physik and Prandtl's article in Aerodynamic theory, edited by Durand (1935). In this decade, about six papers appeared per year on boundary layers. The concept, developed originally for laminar flow, was extended to turbulent flow and also to free shear flows like wakes and jets. An all-inclusive term for such flows is thin shear flows. The stability of laminar flow was also investigated as the cause for origin of turbulence.

During the period 1935 to 1944 , about fourteen papers per year were published on boundary layers (Tani 1977). The analysis of compressible boundary layer was pursued in response 
to need for high speed flight and in later periods to flows with real gas effects. Boundary layer studies were extensively used in aeronautical engineering. Due to study of heat and mass transfer in moving fluids, the application of boundary layers extended, by the 1950's, to mechanical engineering, chemical engineering etc. By 1955 about 100 articles appeared per year on boundary layers. Currently about 800 articles per year appear (Schlichting \& Gersten 2000). Over the years significant advances have been made in the following areas.

(i) Prediction of transition under influence of various parameters like pressure gradient, curvature, compressibility, roughness etc.

(ii) Turbulent boundary layers under the influence of pressure gradient, curvature, compressibility etc.

(iii) Study of thin shear flows like wakes, jets, wake-boundary layer interaction, wall jet etc., subject to effects like curvature, pressure gradient etc.

(iv) Measurement of boundary layers using hot wire anemometer, laser Doppler anemometer (LDA) and particle image velocimetry (PIV).

(v) Three-dimensional boundary layers.

(vi) Unsteady boundary layers with application to rotating machinery and helicopters.

(vii) Atmospheric boundary layers.

(viii) Computation of boundary layer using

(a) Momentum integral equation.

(b) Reynolds averaged Navier-Stokes (RANS) equations which can be derived by decomposing instantaneous velocity and other flow variables as sum of the time averaged part plus the fluctuating part, e.g. $U=\bar{U}+u^{\prime}$.

(c) Direct numerical simulation (DNS) of turbulent boundary layers. In this approach, the unsteady Navier-Stokes equations are numerically solved over a fine grid to resolve the smallest scales of turbulent motion. This approach requires large computational resources.

(d) Large eddy simulation (LES) This approach is in-between the RANS and DNS approaches and involves the resolution of large eddies and modelling the smaller ones.

(ix) Models of turbulence for boundary layers: mixing length, one-equation, two-equation, half equation, Reynolds stress models and nonlinear models etc.

(x) Drag reduction by modification of surface, additives etc.

(xi) Boundary layer control by blowing, suction, moving wall etc.

(xii) Singular perturbation theory and higher order boundary layer.

(xiii) Study of features like presence of coherent structures, intermittency etc.

Description of developments in all these areas would be beyond the scope of this article. The following sub-sections describe some developments of special interest to the author, which also have practical applications.

\subsection{Laminar flow airfoils}

Prandtl (1914) inferred that flow in the boundary layer could become turbulent and that transition to turbulence could be triggered by roughness. Further, he learnt that (i) a turbulent boundary layer has a higher skin friction drag, (ii) separation is delayed when the boundary layer is turbulent. Thus, for a bluff body whose drag in mainly pressure drag, the drag 
is reduced when separation is delayed by triggering transition. However, for a streamlined body like an airfoil, whose drag is mainly skin friction drag, delaying transition to turbulence reduces the drag. Beyond a certain Reynolds number the laminar boundary layer becomes sensitive to small disturbances, and the disturbances grow. Later the boundary layer becomes turbulent. Tollemien (1929) and Schlichting (1933) were able to theoretically calculate the critical Reynolds number (now called indifference Reynolds number, see Schlichting \& Gersten 2000) for a flat plate boundary layer. Subsequently the effect of a pressure gradient was studied by Schlichting \& Ulrich (1940) and it was shown that transition does not take place when the pressure gradient is favourable (i.e. pressure decreases along the flow direction) and that transition is hastened by an adverse pressure gradient (i.e. pressure increases along flow direction). Further transition can be delayed by having a smooth surface. These findings led to development of to laminar flow airfoils by Jacob (1939) and others at NACA laboratories. These airfoils have significantly lower drag coefficient as compared to earlier airfoils. The variations of drag coefficient with Reynolds number and the shape of earlier airfoils (NACA 4 and 5-digit series) and the laminar flow airfoils are shown in figure 6 (Sclichting 1968). Subsequently methods for predicting (a) critical Reynolds number, (b) extent of transition zone, (c) laminar separations and reattachment etc., were improved. Currently, codes are available for design of laminar flow airfoils for desired applications. These codes generally employ momentum integral equation for computing the development of boundary layers. See, for example, Eppler (1990).

\subsection{Slotted airfoils}

Blowing or energizing the low velocity fluid in the boundary layer can delay the separation of the boundary layer. This can be achieved, in a passive manner, by having a slot in the airfoil, which connects the relatively high-pressure region on the lower surface of an airfoil, at an angle of attack, to the low-pressure region on the upper surface of the airfoil. The air from the lower surface rushes to the upper side and energizes the boundary layer on the upper surface and delays separation. This leads to a slat at the leading edge and a slot ahead of the trailing edge flap (figure 7). Developments in measurement techniques have enabled the measurement of this complex flow involving laminar boundary layer, transition, turbulent boundary layer and wake boundary layer interaction. Computational techniques and models of turbulence have also been improved to enable satisfactory prediction. See, for example, Ying et al (1999).

\subsection{Data on two-dimensional boundary layers}

Codes have been developed and are being used to calculate boundary layers. These codes need to be validated for gaining confidence in the prediction of results (Roche 1998). This requires data from carefully conducted experiments. Such data are called benchmark data. Here, we highlight some of these benchmark data. Klebanoff (1955) measured velocity profiles, turbulence stresses, dissipation (partially), and the terms in equation for of turbulent kinetic energy and intermittency in a boundary layer at $R_{\theta}=7500$ where $R_{\theta}$ is Reynolds number based on momentum thickness $(\theta)$ of the boundary layer.

Coles \& Hirst (1969) present a compilation of data on boundary layer subjected to favourable and adverse pressure gradients and relaxing flow where pressure gradient is abruptly decreased and boundary layer relaxes to a new equilibrium.

Samuel \& Joubert (1975) consider boundary layers developing under increasingly adverse pressure gradients. 

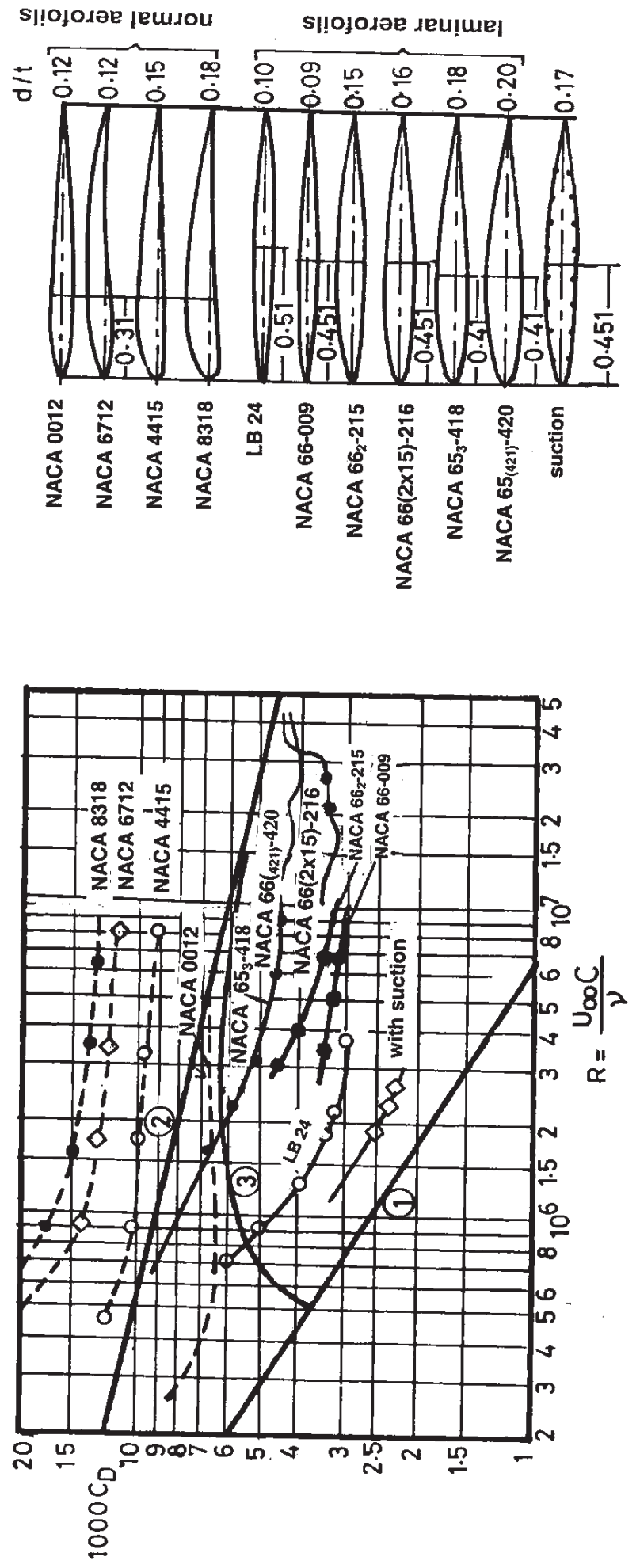


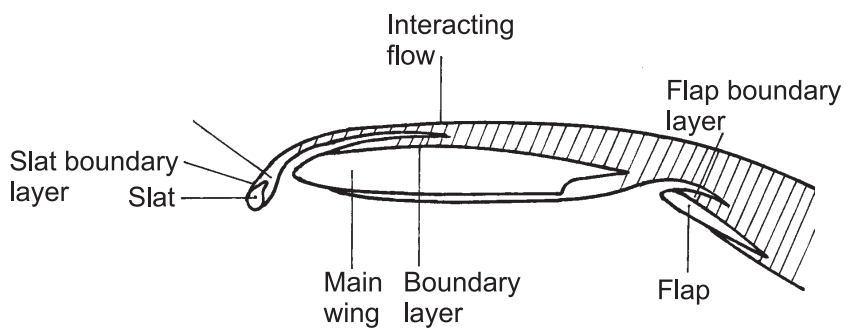

Figure 7. Wake-boundary layer interaction on a multi-element airfoil.

Spalart (1988) presents DNS of zero pressure gradient boundary layer up to $R_{\theta}=1410$. Detailed turbulence statistics regarding velocity and pressure have been deduced. This investigation has provides insights into pressure fluctuations which are not easy to measure. Data have been used to verify models of turbulence. Spalart \& Watmuff (1993) have carried out experimental and numerical studies of boundary layers under pressure gradients.

\subsection{Data on three-dimensional turbulent boundary layers}

Boundary layers over swept wings, yawed cylinders or junctions of two bodies are threedimensional in nature. Measurements are difficult in these flows. Van den Berg \& Elsenaar (1972) have reported measurements on an infinite swept wing shown in figure 8.

Pressure distributions, velocity profiles and turbulent stresses are reported.

Spaid et al (1990) present measurements on models of transport airplane wing-body combinations. The geometry is shown in figure 9. Information on skin friction drag is a special feature of the data. Olcmen \& Simpson (1995) present data on wing-body junctions as shown in figure 10. Data on pressure co-efficient, skin friction, mean velocity and Reynolds stresses measured using three-component LDA are presented. A recent paper (Olcmen et al 2001) presents details on correlations between velocity components. The data should be useful for developing higher level models of turbulence.

\section{Some examples of boundary layer research in India}

Research in the field of boundary layers has been going on for the last fifty years in India. Important contributions have been in (i) transitions from laminar to turbulent boundary layers in incompressible and compressible flow and in three-dimension boundary layers, (ii) reverse transitions where turbulent boundary layers tend to become laminar when subjected to influences like severe favourable pressure gradients and centrifugal force, (iii) boundary layers subjected to curvature, as in flows in curved ducts etc., (iv) measurements of atmospheric boundarys layers, and (v) drag reduction by modification of surfaces on which boundary layers develop. Contributions made by different groups in the country are highlighted below. (References to some of the investigations are cited as illustrations, not all are listed.)

Dhawan (1953) under Prof H W Liepmann developed the technique called "direct measurement of skin friction". After his return to India, he initiated work in boundary layers at the Indian Institute of Science, Bangalore. Dhawan \& Narasimha (1958) carried out a detailed study of transition in boundary layers. Rao (1967) studied an axisymmetric boundary layer. T S Prahlad studied three-dimensional boundary layers and M A B Narayanan and V Ramjee (1969) studied reverse transition. Subsequently, a large number of studies on boundary layers, wakes and jets were carried out under the guidance of R Narasimha, e.g. Prabhu \& 


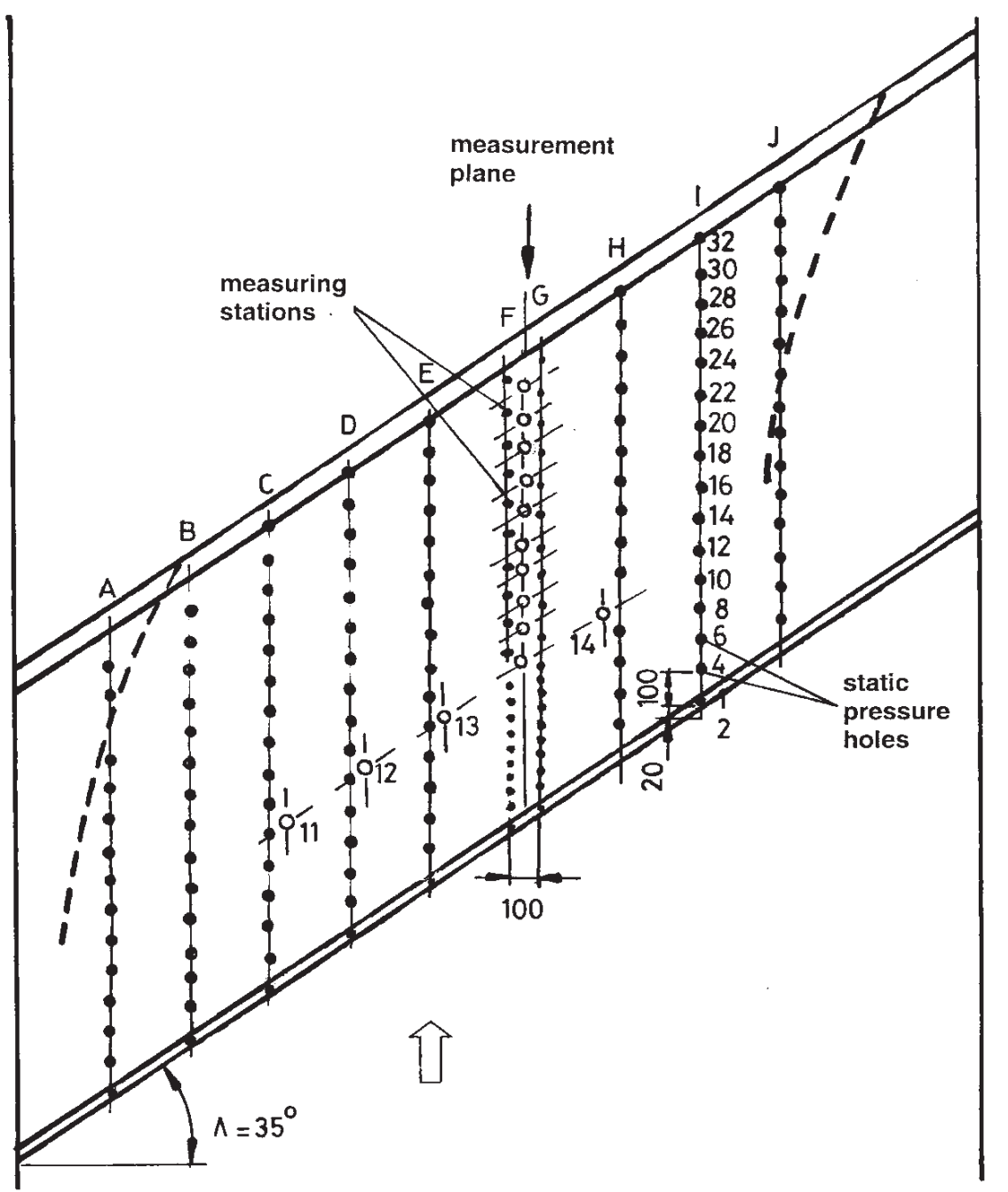

Figure 8. Boundary layer over a swept wing.

Narasimha (1972) on wakes, Rao et al (1971) on phenomenon of bursting in boundary layer. Later R Narasimha, A Prabhu and K N Rao did several studies on atmospheric boundary layers. A Prabhu, and B R Ramaprian have carried out studies on effects of curvature on boundary layers. J Dey and Rama Govindarajan have studied various aspects of transition. Noor Afzal applied asymptotic analysis to boundary layers. Yajnik (1970) extended the asymptotic theory to turbulent shear flows. After joining National Aeronautical Laboratory (NAL, now called the National Aerospace Laboratories), Bangalore he guided research in boundary layers, wakes and wake-boundary layer interactions. At NAL, Bangalore diagnostic techniques like LDA and PIV have been used to study free shear flows. P R Viswanath has worked on drag reduction by modification of the surface and on reverse transition. K Ramamurthy and others at the Computational \& Theoretical Fluid Dynamics Division of NAL have developed codes for laminar flow airfoils. S Majumdar, S K Saxena and others have developed codes for computation of boundary layers over ships, space vehicles etc.. 


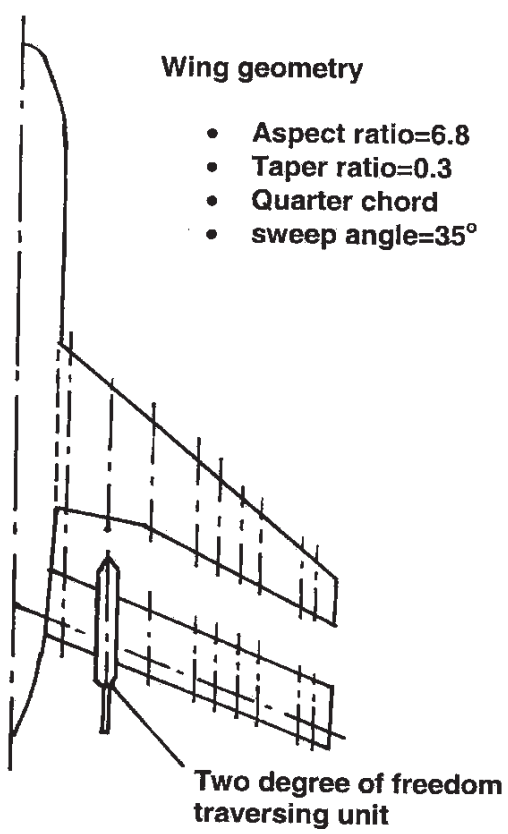

Figure 9. Boundary layer on wing-body combination.

At Indian Institute of Technology Madras, N V C Swamy initiated work on threedimensional boundary layers and wall jets, e.g. Swamy (1971) and Swamy \& Aswathanarayana (1975). B H L Gowda has done several studies on three-dimensional wall jets. E G Tulapurkara, V Ramjee and J L Narasimhan have studied various aspects of boundary layers, wakes and wake-boundary layer interactions subjected to pressure gradient and curvature, e.g. Tulapurkara et al $(1996,2001)$. Studies on flow past S-shaped blades involving convex and concave curvatures in succession and pressure gradient have been carried out.

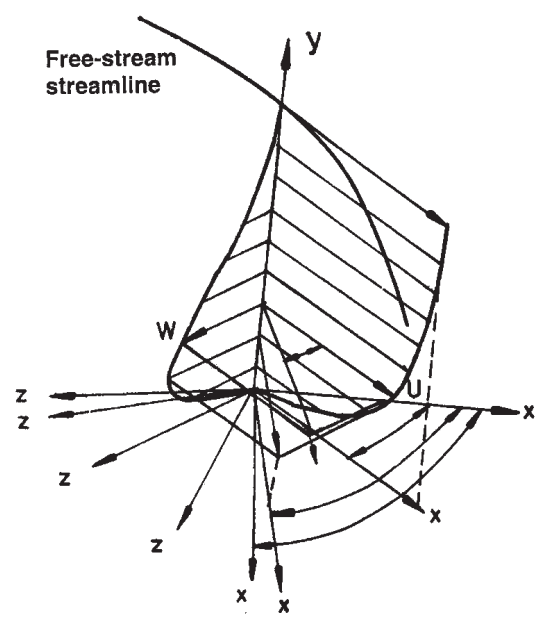

(a)

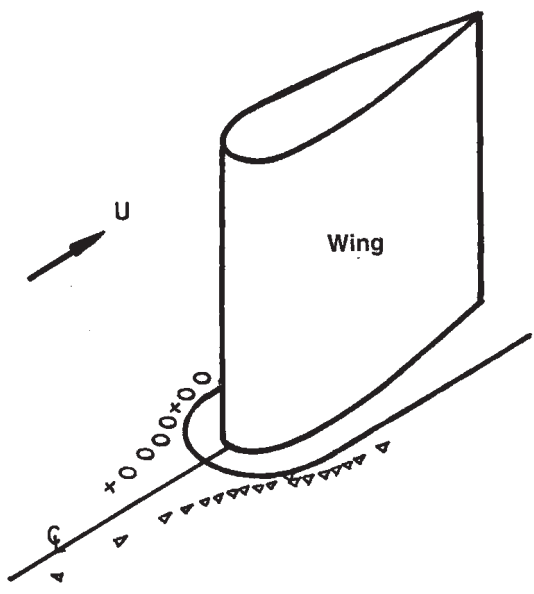

(b)

Figure 10. Boundary layer on a wing-body junction: (a) velocity profiles, (b) junction. 
T K Bose and his students studied boundary layers involving heat transfer, e.g. Bose (1980). B V S S S Prasad and N Sitaram have studied boundary layers on turbo-machinery components. Boundary layers in curved tubes and process equipment have been studied by S Jayanti.

At Indian Institute of Technology, Delhi P K Sen has investigated various aspects of transition e.g. Sen \& Vashisht (1989). S Veeravalli studied the thickest boundary layer developed on the wall of the NASA Ames tunnel (Saddhoughi \& Veeravalli 1994).

Work on boundary layers is going on in many organizations in India. The above description is far from all-inclusive and is only a sample of the work done/going on, as known to the author. Omissions are entirely unintentional.

\section{Concluding remarks}

(1) A single paper (Prandtl 1904) led to developments in several branches of engineering that in itself are a tribute to the genius of Ludwig Prandtl. In the present article, we have touched upon a few aspects of the entire spectrum of applications of the boundary layer concept.

(2) Though several flow situations have been tackled in the literature, there are many areas in which research is continuing. A few of them are: (i) transitions in hypersonic flow, (ii) transitions in three-dimensional boundary layers like those on airplane wings, (iii) computation of three-dimensional turbulent boundary layers, and (iv) thermal boundary layers on porous surfaces with suction.

Help from Manoj Kumar Radle, S Mukhopadhyay and S Rajesh in preparation of this article is gratefully acknowledged.

\section{References}

Anderson Jr J D 1985 Fundamentals of aerodynamics (Singapore: McGraw Hill)

Bose T K 1980 Turbulent boundary layer heat transfer for a constant property particle laden gas flow. Waerme Stoffuebertragung 14: 165-171

Coles D, Hirst A E (eds) 1969 Computation of turbulent boundary layers. Proc. 1968 AFOSR-IFP Stanford Conference (Stanford University, CA: Thermoscience Division)

Dhawan S 1953 Direct measurement of skin friction. NACA Report 1121

Dhawan S, Narasimha R 1958 Some properties of boundary layer flow during transition from laminar to turbulent motion. J. Fluid Mech. 3: 418-436

Elsenaar E, Boelsma S H 1974 Measurement of the turbulent boundary layer under infinite swept wing conditions. NLR TR $74095 \mathrm{U}$

Elsenaar A, Hjelmberg L, Butefisch K, Bannink W J 1988 The international vortex flow experiment. In AGARD CP-437, vol. 1, pp 9.1-9.3

Eppler R 1990 Airfoil design and data (Berlin, Heidelberg: Springer Verlag)

Jacob E N 1939 Preliminary report on laminar flow airfoils and boundary layer investigations. NACA Wartime Report No L-345, quoted in Theory of wing sections by I H Abbott and A E Von Doenhoff 1959 (New York: Dover)

Klebanoff P S 1955 Characteristics of turbulence in a boundary layer with zero pressure gradient. NACA Report 1247

Lumley J L, Yaglom A M 2001 A century of turbulence. Flow Turbulence Combustion 66: 241-286 
Narayanan M A B, Ramjee V 1969 On criteria for reverse trasition in a 2-D boundary layer flow. $J$. Fluid Mech. 35: 235-255

Olcmen S M, Simpson R L 1995 An experimental study of a three-dimensional pressure driven turbulent boundary layer. J Fluid Mech. 290: 225-262

Olcmen S M, Simpson R L, Goody M 2001 An experimental investigation of two-point correlations in two and three-dimensional turbulent boundary layers. Flow Turbulence Combustion 66: 85-112

Prabhu A, Narasimha R 1972 Turbulent non-equilibrium wakes. J. Fluid Mech. 54: 19-38

Prandtl L 1904 Uber Flussigkeits bewegung bei sehr kleiner Reibung. Verhaldlg III Int. Math. Kong. (Heidelberg: Teubner) pp 484-491; Also available in translation as: Motion of fluids with very little viscosity. NACA TM 452 (March 1928)

Prandtl L 1914 Der luftwiderstand von Kugeln. Nachr. Acad. Wiss. Göttingen, Math. Phys. 177-190

Prandtl L 1925 Bericht uber untersuchungen zur ausgebildete Turbulenz. ZAMM 5: 136-139

Prandtl L 1945 Über ein neues formel system fur die ausgebildete Turbulenz. Nachr. Akad. Wiss. Göttingen, Math. Phys. 6-19

Rao G N V 1967 The law of the wall in thick axisymmetric turbulent boundary layers. J. Appl. Mech. 89: 327

Rao K N, Narasimha R, Badrinarayanan M A 1971 The bursting phenomenon in a turbulent boundary layer. J. Fluid Mech. 48: 339-352

Roche P J 1998 Verification and validation in computational science and engineering (New Mexico: Hermosa)

Rouse H, Ince S 1963 History of hydraulics (New York: Dover)

Saddoughi S G, Veeravalli S V 1994 Local isotropy in turbulent boundary layer at high Reynolds number. J. Fluid Mech. 268: 333-372

Samuel A E, Joubert P N 1975 A boundary layer developing in an increasingly adverse pressure gradient. J. Fluid Mech. 66: 481-505

Schlichting H 1933 Zur entstchung der turbulenz bei der plattenstromung. Z. Angew. Math. Mech. 13: 171-174

Schlichting H, Gersten K 2000 Boundary layer theory (Berlin, Heidelberg : Springer Verlag)

Schlichting H, Ulrich A 1940 Zur Berechnung des umschalages laminar-turbulent. Report 510 of Lilienthal-Gessellschaft 75-135

Sen P K, Vashist T K 1989 On nonlinear stability of boundary layer flow over a flat plate. Proc. R. Soc. London A424: 81-92

Spaid F W, Roos F W, Hicks R M 1990 An experimental study of the turbulent boundary layer on a transport wing in subsonic and transonic flows. NASA TM 102206

Spalart P R 1988 Direct numerical simulation of boundary layer upto $R_{\theta}=1410$. J. Fluid Mech. 187: $61-98$

Spalart P R, Watmuff J H 1993 Experimental and numerical study of a turbulent boundary layer with pressure gradient. J. Fluid Mech. 249: 337-371

Swamy N V C 1971 Turbulent boundary layer on a yawed flat plate. Z. Flugwiss. 19: 496-502

Swamy N V C, Aswathanrayana P A 1975 Turbulent boundary layer over yawed plates at incidence. ZFW 23: 400-408

Tani I 1922 History of boundary layer theory. Annu. Rev. Fluid Mech. 9: 87-111

Tollmien W 1929 Uber die enstehung der Turbulenz 1 Mitteilung. Nachr. Acad. Wiss. Göttingen, Math. Phys. 21-44

Tulapurkara E G, Ramjee V, George J 1996 Prediction of airfoil wake subjected to the effects of curvature and pressure gradient. Int. J. Numer. Methods Fluids 22: 29-41

Tulapurkara E G, Khoshnevis A B, Narasimhan J L 2001 Wake boundary layer interaction subject to convex and concave curvatures and adverse pressure gradient. Exp. Fluids 31: 697-707

Van den Berg B, Elsenaar A 1972 Measurements in a three-dimensional turbulent boundary layer under infinite swept wing conditions. NLR TR 72079U

Yajnik K S 1970 Asymptotic theory of turbulent shear flows. J. Fluid Mech. 42: 411-427

Ying S X, Spaid F W, McGrinley C B, Rumsey C L 1999 Investigation of confluent boundary layers in high-lift flows. J. Aircraft 36: 550-562 